\title{
DOSS||̂ิ
}

Sociologias, Porto Alegre, ano 8, no 15, jan/jun 2006, p.56-87

\section{La complejidad en la totalidad dialéctica}

CARLOS MASSÉ NARVÁEZ

\section{Introducción}

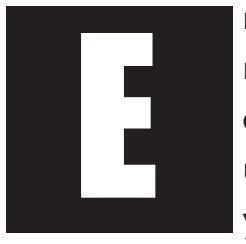

n general consideramos que el uso a-crítico de metodologías rígidas (como la del mal llamado "método científico, pues existen las metodologías de las diversas ciencias y no la unidad de método); limita la construcción de conocimiento

y que, a la inversa, el pensar abierto y crítico es mucho más rico. Pero no todo pensar permite la apertura de la razón, por lo que la epistemología que nos proponemos propugnar, es el uso de la totalidad dialéctica (TD), como dispositivo de reducción de la complejidad de la realidad, en aras de su comprensión. ${ }^{1}$ Puesto que ella implica una forma de apropiación de la realidad con base epistemológica.

\section{1. ¿Para qué estudiar la Epistemología?}

Muchos autores utilizan el término epistemología para designar a la "teoría del conocimiento" o "gnoseología", es decir, un sector de la filosofía que examina el problema del conocimiento en general: el ordinario, el filosófico, el científico, etc. Pero, en general, el término epistemología es

\footnotetext{
* Doctor en Sociología por la Universidad Nacional Autónoma de México (UNAM). Investigador del Centro de Estudios de la Universidad de la UNAM y miembro del Sistema Nacional de Investigadores - SNI ( SEP- CONACYT-MÉXICO). México.

1 Aquí consideramos que la totalidad dialéctica, solo puede devenir de la Epistemología Dialéctica Crítica; esta e una visión cognitiva y una posición con respecto a los fundamentos de un conocimiento crítico que deviene principalmente de Hegel, Marx, Kosik, Zemelman y Covarrubias y quien suscribe.
} 
empleado en un sentido más restringido, referido exclusivamente a los problemas del conocimiento científico, tales como las circunstancias históricas, psicológicas y sociológicas que llevan a su obtención y los criterios con los cuales se lo justifica o invalida. La epistemología es entonces, en alguna forma -aunque no sólo sea eso-, el estudio de las condiciones de producción y validación del conocimiento científico.

Se pueden encontrar incontables obras con sus diversas posiciones y proposiciones de cómo es la mejor manera de hacer ciencia o, llegar al conocimiento científico. También existen publicadas una buena porción de disputas metodológicas que -obviamente-implican la discusión epistemológica, por lo que; en este trabajo sólo nos ocuparemos de intentar una caracterización de una (TD) posible, ${ }^{2}$ con base en la búsqueda de los sustentos que la configuran. Esto porque la ciencia requiere de la filosofía para sustentar la validez de sus proposiciones y el campo de la filosofía que aborda este problema es la epistemología.

Nadie desconoce que las ciencias sociales en sus orígenes, han tomado las bases epistemológicas de las ciencias naturales; por ejemplo, es conocida la interpretación determinista del mundo social que asume el positivismo, precisamente con base en el traslado mecánico del esquema epistemológico de la física newtoniana -hoy en decadencia-, en la cual la acción de las leyes es ineluctable y objetiva, ausente de toda posibilidad de intervención subjetiva. Lo cual como se verá, fue un error histórico). Según Edgar Morín:

En efecto, la ciencia occidental se fundó sobre la eliminación positivista del sujeto a partir de la idea de que los objetos, al existir independientemente del sujeto, podían ser observados y explicados en cuanto 
tales. La idea del universo de hechos objetivos, liberados de todo juicio de valor, de toda deformación subjetiva, gracias al método experimental y a los procedimientos de verificación (...) Dentro de ese marco de referencia, el sujeto es, o bien el "ruido", es decir, la perturbación, la deformación, el error, que hace falta eliminar a fin de lograr el conocimiento objetivo, o bien el espejo, simple reflejo del universo objetivo (1997: 65).

Es necesario examinar entonces los fundamentos epistemológicos de las ciencias, y la evolución que han registrado sus fundamentos, para obtener una mayor claridad en nuestro análisis. Desde Aristóteles, la episteme es el conocimiento verdadero, es conocimiento de lo universal, de lo que existe sin variaciones, de lo que trasciende. Este ha sido el faro orientador de los grandes científicos de la antigüedad que fundamentaron el edificio de la Ciencia. Precisamente se proponían encontrar la piedra angular, que sustentara sobre sí misma toda la estructura de la ciencia; lo que de lograrse le daría seguridad y proporcionaría estabilidad permanente, ante las turbulencias y dudas que continuamente la amenazaban. Desde entonces, con Heráclito, ${ }^{3}$ surgía el pensamiento dialéctico en aquélla célebre frase "nadie se baña dos veces en el mismo río". ${ }^{4}$

Ello implicaba a los elementos que años más tarde abrirían para siempre el debate sobre los fundamentos del conocimiento: el problema del tiempo (pasado - presente - futuro), el de la historia como especificidad. El río en

\footnotetext{
3 Hacia finales del siglo VI o comienzos del V, Heráclito (c. 544 - 484) contradice todo lo anterior afirmando que nada es permanente y no existe armonía. Lo que vive, vive por la destrucción de otra cosa. El fuego vive por la muerte del aire. Lo que parece armonía es tensión de opuestos. La base del equilibrio es la lucha; la lucha es buena en sí puesto que es la fuente de la vida. La arjé (principio) ya no es agua o aire o apeiron sino devenir puro, mero fluir. (http://www.antroposmoderno.com/antroarticulo.php?id_articulo=625)

4 Ello planteó el problema del tiempo y del movimiento Hasta entonces los filósofos han buscado algo permanente para explicar el mundo en que vivían, a lo que Pitágoras ha añadido el orden y la armonía. Pero, mientras los atenienses avanzaban hacia su democracia, el pensamiento griego en general también se desarrollaba y ya no resultaba natural aceptar una única sustancia material como principio de todo. Además, las explicaciones que daban de la variedad de las cosas, de sus cambios y movimientos, no parecían convincentes. Surgieron así nuevos filósofos que trataron de responder a esas preguntas
} 
que hoy me baño, no es el mismo de ayer ni, será el mismo mañana. Una multiplicidad de especificidades por cada lapso temporal.

Por su parte, Platón formuló su teoría de los cuatro estados mentales, a saber: Ilusión (eikasia), creencia (pistis), razón (dianoia) y pensamiento puro (episteme), de esta forma, la episteme o epistemología surge como la explicación de un estado superior de la abstracción mental para la elaboración del conocimiento. Por otra parte, Aristóteles, quien buscaba los principios formales del ente y su comprensión, encontramos los orígenes de la epistemología como teoría del conocimiento; es decir, uno de los objetivos originales de la epistemología es el de encontrar la fundamentación primaria de los conocimientos, porque, sin presuponer un comienzo desde el cual hay que inferir el desarrollo de la ciencia, no era posible llevar a cabo ninguna inferencia. Entonces la búsqueda de la seguridad del conocimiento fue la preocupación original de la epistemología. (Ver Gutiérrez: 2002).

Las tareas de la epistemología se han multiplicado con el paso de la historia, ya no solo atiende a esa preocupación central sino también a las implicaciones de la vinculación entre el sujeto investigador y el objeto de estudio, pero también a la justificación, coherencia, legitimidad y rigor de la cientificidad de un campo determinado del saber; Otras acepciones más amplias otorgan a la epistemología el nivel de una metaciencia, que tiene por objeto dictar desde el exterior del proceso de la investigación, la normatividad general a la que este debe ajustarse para "asegurar" su cientificidad.

\section{La limitación de los discursos disciplinarios}

En la obra: Del algoritmo al sujeto, se plantea la existencia de dos tipos de investigaciones científico sociales: una que es mayoritaria (de primer orden) y que es descriptiva y funcional (le sirve al sistema de cosas); la otra, 
es crítica y reflexiva (de segundo orden). El trabajo de ésta última es mucho más profundo. A la vez que construye conocimiento crítico (subversivo del orden social), conlleva una reflexión sobre cómo lo está construyendo.

...el problema no es que se utilicen palabras o números (evidentemente con números no se puede interpretar y con palabras no se puede describir con precisión), sino que el investigador piense o no piense lo que hace: el que reflexiona sobre su acción investigadora se acerca al segundo orden, y el que no lo hace, se acerca al primer orden (Ibáñez: 1985: XVIII).

Esta mayoría de científicos que trabajan con esa forma de concebir la realidad y la ciencia, en las escuelas universitarias o en los institutos de investigación se encuentran —aún hoy_ al menos en México, pero creemos que en todo el tercer mundo al menos $y$, se asumen parcelados y en el mejor de los casos sobrepuestos pero sin abandonar la visión parcelaria de la ciencia. Pero este problema ha sido ya considerado tiempo atrás:

Se dice que la especialización científica permite la profundización en el conocimiento de pequeñas regiones de la realidad. El argumento se apoya en el criterio de productividad cognitiva, pero veamos qué hay detrás de todo esto. Benjamín Farrington, estudioso de la filosofía clásica y de la ciencia y la política en el mundo antiguo, reprocha a Darwin su escasa cultura general y su ignorancia de la filosofía de la ciencia, lo cual le impidió percibir con precisión su deuda científica y los alcances y limitaciones de sus descubrimientos. Mendel, inspirado en El origen de las especies por selección natural de Darwin y contemporáneo suyo, descubrió las leyes básicas de la genética, desconocidas por Darwin (Covarrubias: 1995 b), pp. 56). 
El proceso es claro, se trata de establecer una integración horizontal de las ciencias pues de lo contrario tendemos al estancamiento. Un ejemplo del problema, lo constituyen los campos altamente interdisciplinarios que no pueden ser comprendidos, ni estudiados, desde una sola ciencia, ni en dos ni en tres; sino que constituyen totalidades complejas que implican una nueva forma de concebir la estructura de las ciencias. Pero lo interdisciplinario también tiene sus problemas. Sólo para dejarlo apuntado, hago la siguiente pregunta ¿Cómo podrán conciliarse los supuestos de los distintos discursos sustantivos (disciplinarios), en aras de por ejemplo, unificar un método, que se proponga útil para el abordaje de un problema que requiere de intervención interdisciplinaria. Por nuestra parte, más adelante propondremos a la articulación transdisciplinaria, con base en la totalidad dialéctica.

En (Auto) crítica de la ciencia, biólogos, físicos, químicos y matemáticos, plantean cómo en sus espacios de investigación se ha llegado a una enorme enajenación a causa de la fragmentación cognitiva, producto de la división técnica del trabajo de investigación. Los científicos estaban horrorizados del uso militar de sus descubrimientos y de lo poco que entienden de otros ámbitos de la realidad. Lo mismo ocurre en las ciencias sociales. Los sociólogos por ejemplo, han sido divididos en educativos, rurales, urbanos, de la cultura, del conocimiento, etcétera. En donde el sociólogo de la educación nada sabe de sociología política (por que no es "su" campo). El economista internacional, poco o nada sabe de economía financiera, ya no se diga de filosofía o de ciencia política.

La ciencia parcializada es cada vez menos capaz de comprender la esencia de los sistemas complejos, por ejemplo, todos los sistemas organizados en forma de red, como las redes neurales, los sistemas financieros y bancarios internacionales, las interrelaciones de la física cuántica, las redes sociales, y otras, en las que no existe organización piramidal sino horizontal, requieren para su mejor comprensión y análisis de una nueva visión de la 
realidad científica, una nueva visión global y totalizadota. Jesús Ibáñez explica en su perspectiva el por qué de ese problema:

En el protocapitalismo, la investigación empírica se aplica al descubrimiento de nuevos hechos brutos, es adisciplinaria y ametódica; en el capitalismo de producción y acumulación la investigación es disciplinaria y metódica, la continuidad de fondo es sostenida por la continuidad de método. El saber académico aparece como discontinuo, distribuido en parcelas disciplinarias, reflejo de la división del trabajo: los especialistas de una disciplina tienen la propiedad privada del objeto de esa disciplina, en los dos sentidos del término < privada > , privan a los demás sujetos o especialistas del acceso a esa parcela (en la perspectiva de la división del trabajo), y privan al objeto de todo resto no contabilizable y/o conmensurable (en la perspectiva de la operación metodológica de construcción de un objeto formal o de conocimiento (Ibáñez: 1985, p. 58).

Consideramos que lo expuesto es suficiente para entender por qué nuestro interés en propugnar a la epistemología dialéctica crítica (EDC), como una propuesta de conocimiento enriquecedora en términos de ofrecer, una forma diferente y potente de apropiación de lo real. Pues no se ciñe a la rigidez metodológica, sino que propugna por una apertura del pensamiento a la realidad, sin ataduras procedimentales; pues otorga al objeto, "la cosa misma", toda la apertura mental posible, en aras de apropiarse de todo el desenvolvimiento de dicho objeto, el cual nos conducirá al descubrimiento de su lógica. Objeto del que el sujeto con el andamiaje epistemológico que propondremos, también forma parte.

\section{Epistemología y filosofía: Realidad, Presente y Utopía}

En este apartado nos ocupamos de plantear la importancia del nivel temporal en su vínculo con la realidad como aquí la concebimos, ambos en 
la dimensión de la epistemología dialéctica crítica; y de la vulgar distinción del simple sentido común, que supone, "aclara" lo que "es" la realidad, "distinguiéndola" de lo que es una utopía.

Sólo en una perspectiva que concibe a la realidad en movimiento, es comprensible el tiempo presente como aquí lo concebimos. En ese sentido, el primer problema que se nos presenta es cómo representar ese movimiento en el presente cuando la realidad está dada, pero a su vez está dándose. La respuesta a esta representación del movimiento se encuentra en la forma que adquieren ambos momentos en indisoluble vinculación. En ese vínculo se encuentra la potencialidad que orienta la dirección de un campo de acción entre actores, pero esta no es manifiesta. Sin embargo, es un contenido emergente. Lo que Hegel (1978) llamaría el lugar de las transformaciones cualitativas. Lo que para Bloch (1983) sería "lo novum".

Este último concepto emerge del Filosofo de la Utopía a raíz de la búsqueda de la utopía concreta. La utopía tiene un sentido peyorativo solo si se entiende como mera ilusión y deseo de lo óptimo, sin ninguna probabilidad de realización y sin ningún motor práctico. Lo que sería la utopía abstracta.

La utopía genuina o utopía concreta emerge con base en un ideal abstracto para convertirse en un futuro concreto. Utopía concreta es lo realmente posible en un mundo malo y falso. Este mundo malo y falso es la realidad dada y la utopía concreta es la posibilidad de arribar a ese mundo bueno que estaría por darse con base en la práctica concreta, la que puede ser viable conociendo el vínculo entre lo que está dado y lo que está dándose.

Si los actores que aspiran a incidir en la realidad pueden rescatar ese vínculo entre lo producido y lo que se está produciendo, pueden con ello incidir en lo que está por darse (futuro). De ahí que la diferencia entre la perspectiva presente-pasado y perspectiva presente-futuro radica, en que en la primera hay una realidad producida (un topos) y en la segunda aún no deviene la realidad (no es una empiria). 
"Topos" (el lugar) es el objetivo empírico. Pensar la realidad como un topos, como un dato objetivo o con una perspectiva objetivista, diagnosticarlo y pronosticarlo a partir de la objetividad, es ya, estructuralmente quedarse enraizado en el mismo lugar.

Se ha olvidado el futuro porque no sabemos la naturaleza de los datos posibles y no obstante, la discusión cotidiana entre los distintos actores sociales no se da sólo sobre el pasado (a excepción del trabajo académico de los historiadores). En este punto surge la pregunta ¿̇ómo incorporar la dimensión gnoseológica a la dimensión del futuro?

La respuesta está en Bloch. En él, la utopía es un concepto dual. No aquí y ahora (sentido negativo) de la realidad y, por inferencia, si allá y después (sentido positivo). Un negativo al comienzo, una negación en el proceso y por ello, un posible futuro positivo. Es por eso que el concepto de lo no existente también puede ser objeto de conocimiento científico.

En esta perspectiva -a la que nos adherimos-, no busca tanto organizar una visión de futuro sino de construirlo, aunque para ello la visión es una cuestión ineludible. Sin embargo, no hay que creer que teniendo un modelo de futuro, con ello lo vamos a construir, pues no todos los proyectos son viables si tomamos en cuenta que en la relación dialéctica sujeto-objeto interviene lo contingente, el azar. Además se debe tener en cuenta que el sujeto (psicológico, institucional, ideológico, religioso, económico y cultural), el individuo, actúa con sus subjetividades en la realidad objetiva.

\section{La producción de conocimiento científico}

A toda construcción de conocimiento corresponde una concepción ontológica de la realidad y su estructura, es sumamente compleja. Esta se integra en el bloque de pensamiento con referentes contradictorios, en el que uno de ellos da sentido y funcionalidad a los demás, por lo tanto, es 
hegemónico. Pero un conocimiento no se integra solamente por elementos constitutivos de un solo paradigma sino que contiene referentes que provienen de otros modos de apropiación. De ahí que, entendemos por concepción ontológica el conjunto de ideas que los seres humanos tienen respecto al ser y a sus formas de existencia. Sin embargo, dichas ideas pueden encontrarse de manera caótica en el pensamiento sin constituirse en discurso lógico o aparecer ordenadas en un sistema racional.

Precisamente, el concepto de hegemonía tal como lo reelaboraron Ernesto Laclau y Chantal Mouffe permite visualizar el campo de las ciencias sociales y los resultados de sus investigaciones como un espacio privilegiado para la construcción de articulaciones hegemónicas y contra-hegemónicas. Quiere decir, un espacio en donde lo que muchas veces es mostrado como una verdad objetiva legitimada por su carácter científico, es en realidad una representación hegemónica, una construcción históricamente determinada. (Ivanier: 2004).

Las concepciones ontológicas son la base del conocimiento teórico. Las diferencias de interpretación se expresan como discursos teóricointerpretativos y como prácticas políticas distintas y a veces contrarias entre los grupos partidarios de cada una de ellas. Los científicos al igual que todos los seres humanos están determinados por la sociedad en que viven:

... la conciencia teorizante se integra con referentes de la empiria, la religión, la teoría y el arte formando un bloque de pensamiento en el que los referentes teóricos establecen la logicidad con que opera la conciencia (Covarrubias: 1995 b), 113).

Todos los discursos están llenos de múltiples componentes disímiles provenientes de diversos procesos cognoscitivos. De ahí que, los referentes señalados por Covarrubias contienen referentes ontológicos y gnoseológicos constituyentes de bloques de pensamiento en donde los 
referentes de uno de los modos, es el que predomina y los demás son subordinados.

Así como existen referentes teóricos también existen referentes ateóricos integrados en la conciencia teorizante y esto es inevitable por el carácter histórico-social de la teoría y de los teóricos. No existen constructos puramente científicos pues hasta los paradigmas de la ciencia corresponden a las épocas históricas en que fueron elaborados.

El científico tiene un constructo que si se analiza, muestra las contradicciones y la heterogeneidad de su estructura, siendo varios los problemas:

a) el de la presentación del constructo teórico ontológico;

b) el del teórico epistemológico;

c) el de la presentación del discurso sustantivo,

d) el de la homogeneidad científica de cada uno;

e) el de la correspondencia lógica entre las partes; y

f) el de la eliminación de elementos no científicos (que siempre están presentes en el sujeto pero que no aparecen en el discurso del científico.

Cada forma de la conciencia contiene referentes de modos de apropiación subalternos sin que ello signifique su identidad: cada una se define por los referentes relevantes que la constituyen y determinan. Toda teoría es producto de un despliegue epistemológico fundado en una concepción ontológica existente con anterioridad a su formulación, que opera en la conciencia como preconcepción constituida por referentes propios de distintos modos de apropiación de lo real (Covarrubias: 1995, b;) 113-114.)

Dichas preconcepciones conllevan ideas acerca de la naturaleza del conocimiento científico, y de las formas de existencia de la realidad e intervienen activamente en al formulación de teorías. "Los conocimientos 
(y discursos) -nos dice Olivé)—se producen a través de procesos en los que se transforman en ciertos materiales. Estas materias primas están formadas por los datos empíricos, los conceptos y los discursos proporcionados por las prácticas ideológicas y científicas. El entramado epistemológico, sobre todo a través de la selección, influyen en la formación y en el ordenamiento real de estas materias primas; por ejemplo, en el modo de reunión de los datos empíricos, en cuáles sean los datos que se reúnan, y cuáles queden excluidos, de igual manera, en la selección exclusión de conceptos. Este entramado, en la medida en que también influyen concepciones ontológicas, somete a los conceptos que ingresan en el discurso sociológico que se está produciendo, a nuevas relaciones conceptuales que afectan realmente a su significado; es ésta una de las formas como el entramado epistemológico interviene para transformar los conceptos sacados de la materia prima en su paso hacia el discurso sociológico" (Olivé: 1985, 270). Aunque los planteamientos de Olivé se refieren al discurso sociológico, creemos que son válidos para todo discurso teórico disciplinario.

Aunque la realidad es vivida por cada individuo en sociedad, es ésta quien constituye la individualidad y la realidad. Esta a su vez, puede ser pensada por diversos modos de apropiación por distintos individuos, pero la generación del pensamiento, y de las interpretaciones, sean cuales sean éstas, se producen en la sociedad como totalidad. Esto lo consideramos así, pues como señala Covarrubias:

La realidad social es totalidad orgánica, unidad contradictoria deviniente. El devenir se expresa en momentos que el pensamiento denomina etapas y que, como condensaciones específicas de la totalidad, son unidades contradictorias irrepetibles. El desarrollo histórico no es más que el proceso de transformación de la realidad hecho pensamiento. La historia al igual que la contradicción, el movimiento y el cambio, no son 
sujetos en sí que dirijan y gobiernen a los seres humanos; son categorías que representan los procesos de la realidad. De esta forma, la historia, el movimiento y la contradicción no hacen nada; es el hombre concreto quien hace, y cuya actividad se realiza en el movimiento, el cambio, la contradictoriedad y la historia $(1995, b), 225,226)$.

De manera similar, otro autor señala que:

en toda historia, tanto natural como cultural, que está produciéndose, actúa la ya producida. El hombre es siempre producto y productor de su historia, forma impresa relativamente constante que viviendo se desarrolla. Lo devenido no es algo simplemente pasado, que aparezca frente al sujeto histórico como un objeto extraño a él (Heller: 1983; 21).

Así las cosas, la historia es entonces, a la vez, un proceso creado y creador del hombre. Desde la perspectiva dialéctica, la cosa es en sí cuando es para el hombre; es decir, cuando se ha convertido en objeto de la conciencia, en figura de pensamiento.

Poco o nada -nos dice Covarrubias—se puede decir, de la cosa en sí fuera de la conciencia. La cognición de la cosa en sí se inicia con la sensación y, de manera creciente, la conciencia va apropiándose de las formas y contenidos del objeto. Lo particular es conocido en la especificidad que es generalidad y lo general en lo concreto que es condensación de lo total. El conocimiento que llega a la formulación de conceptos arranca siempre de lo específico como inmediatez y regresa como conocimiento concreto $(1995,227)$. 


\section{La contradictoriedad de lo real}

Los individuos, al ser diferentes unos de otros física y mentalmente, al participar en la única realidad que podemos hacerlo, no obstante lo hacemos de diversas maneras. La heterogeneidad entre individuos, lo es interior en cada uno y en la sociedad como conjunto. No es ésta, una pura contradicción lógica entre individuo y sociedad; se trata de una contradicción ontológica que es fuente de la unidad de lo real como un todo, que se reproduce en el individuo, también de forma condensadamente contradictoria.

La realidad social como unidad contradictoria se produce y se reproduce en la contradictoriedad como totalidad y en la especificidad como heterogeneidad y multiplicidad. A ello se debe la diversidad existencial entre los seres humanos: a la multiplicidad condensatoria de lo real social en los sujetos. Esta contradictoriedad es una realidad objetiva, existente; i.e., la contradicción no es un sujeto, una fuerza o un ser ajeno a la materialidad y distinto a ella; la contradictoriedad es relación entre distintos que se niegan e integran en unidad. Por eso es que la sociedad es la expresión más enriquecida de ella . La riqueza de la contradictoriedad social se condensa en las clases sociales y en las luchas que entre ellas se entablan mas no se agota ahí. Cada clase social se integra por individuos que a la vez pueden ser nuevamente estratificados y que, aun en el nivel más particular de jerarquización sigue predominando la multiplicidad y la heterogeneidad entre ello (Ibidem, 224)

El contexto general en que se desarrollan las interacciones entre los distintos grupos y clases sociales, es el mismo en el que el proceso de constitución de conciencias a través de la educación, pero también massmediatico, se realiza por medio del aparato de hegemonía cuya máxi- 
ma capacidad y eficiencia la ha alcanzado en la actual globalización económica; y la inserción cotidiana de cada vez más ciudadanos al uso intensivo de las nuevas tecnologías como la Internet. El flujo acelerado y acrítico de la información; se erige en forma predominante de detentación y ejercicio del poder político - militar. Cambian las tecnologías, no así las estructuras de control y dominación. Estas sólo se perfeccionan o adecuan, mientras no surja una fuerza capaz de transformarlas.

En esa dirección, los modos de apropiarse de lo real son institucionalizados en la organización hegemónica, sin escapar casi nada a su esfera de control. No obstante, las concepciones negadoras de la razón instrumental predominante, son generadas también en las instituciones.

La contradictoriedad de los referentes generados por los distintos modos de apropiación no son objeto de tratamiento igual por el aparato de hegemonía. El aparato de hegemonía difunde determinados referentes con mayor insistencia, mientras que otros son objeto de ocultamiento, deformación o de una limitada difusión....La homogeneidad de la conciencia y la homogeneidad entre conciencias es imposible (Covarrubias: 1995, 33).

\section{Esperanza y Utopía}

De cara a este aparente insuperable escollo estructural de la sociedad capitalista, recurrimos al pensador de El principio esperanza: Bloch (19541959). Según el filósofo alemán hay que sustituir la anámnesis ${ }^{5}$ especulativa y teórica por la praxis material e histórica, para inaugurar al ser como proceso, como un ir siendo, para llegar a ser; y viceversa. O sea, el método de la 
praxis está emparentado con un sistema ontológico. Y el nombre de esa ontología abierta es utopía.

La utopía genuina o utopía concreta surge cuando un ideal abstracto psicológicamente deseado se convierte en un futuro concreto, prácticamente realizable; cuando lo ideal y atemporal, pasa a ser lo posible real y el futuro. Posibilidad real y realidad posible.

A causa de Marx, el sujeto, ensalzado por Kant en su autonomía respecto al mundo y a la historia pasa a englobarse dentro de la objetividad de un mundo que es la historia humana en desarrollo (Aguilar: 1977, 27).

Según Aguilar cualquier lectura topográfica implica una lectura utópica -en el pensamiento de Bloch—; la lectura de un hombre irrealizado, negado, nonato, perdido y lejano de sí mismo; la lectura de una realidad social inhóspita, antisocial, desierta, deshumana -“tierra pero no Patria"—. Aquí la verdad es dialéctica y, por ello no ideológica).

La fuerza de la dialéctica está en que parte y se desarrolla por la fuerza de lo negativo y por la capacidad de negación de lo negativo; y la utopía del sujeto al interior de la utopía social tiene dicha fuerza, porque la sociedad no es algo dado y perdurable, ni una esencia natural e inmutable, ni creación alguna obra de dioses, sino producto de la praxis humana y material.

Una realidad material y humana no es simplemente lo "dado", algo con contextura y límites definitivos y perceptibles. A la inversa, es $<$ frontera $>$, que, como su nombre señala, es un $<$ hasta aquí se ha llegado $>$, $y<$ horizonte $>$, que es lo $<$ novum $>$ hacia el que tiende. No hay realismo si no se entiende como algo inacabado y en trance de realización. Con esa base puede Bloch tachar de tautología el principio de identidad de la lógica tradicional: No aceptar su proposición $\mathrm{A}=\mathrm{A}$, sino $\mathrm{A}=$ a todavía no $\mathrm{A}$. (González: 1979). 
Supeditado entre el pasado y el futuro, lo $<<$ dado $>>$, el presente, adquiere una significación nueva. La relación entre pasado y presente no es la relación clásica de un proceso que camina hacia un $<<$ resultado $>>$ en el sentido hegeliano, sino un paradigma de cómo las posibilidades de un presente se van necesariamente haciendo futuro, no en el mero vislumbre subjetivo de algo ignoto, sino la reflexión de la propia estructura de su ser. Quien ignora este movimiento se cierra toda posibilidad de conocimiento de lo real (Gonzáles: 1979: 51).

En Bloch la esperanza es el motor de la mediación entre no ser y llegar a ser. Entre A (lo todavía- no-conciente) y su correlato histórico (lo que todavía no es), no se encuentra la determinación de hechos ni la presunción imaginativa, sino la mediación, la esperanza. La esperanza, aún siendo un movimiento psíquico, no queda reducida al ámbito psicológico, y no sólo se diferencia de la espera sino que se realiza en un mundo distinto de significaciones. La esperanza blochiana, es primeramente un modo de conciencia, no una figuración, y sólo es pensable, por eso, como concreta, como referida a una realidad y a una especificidad histórica.

La esperanza como mediación no es sólo cognitio, modo de conocer, sino ímpetus, motivo de la acción. La mediación entre el sujeto como la posibilidad real de todo lo que se ha hecho de él en su historia y la materia como la posibilidad real de todas las conformaciones latentes en su seno, no es sólo la de la conciencia cognoscente, sino sobre todo, la de su prueba o verificación (ver González).

En este principio: la esperanza, el ser es, la utopía de sí mismo. En donde el ser es la materia y ésta, es la utopía de su forma. Es la "materia primera" o sustrato del mundo que inspira y permea todo el mundo y la historia social, con la fuerza de una universal aspiración a "la patria de la identidad". 
Con ese motivo, la actitud a tomar es la esperanza, no como pasiva, expectativa de algo que en el porvenir podrá acaecer sin nosotros, sino como praxis revolucionaria cierta de su éxito futuro, como una opción militante, como algo ya positivo que puede suceder a condición de desenmascarar, y negar la negatividad de este mundo histórico que es. Por lo pronto, el mundo es hasta aquí, el laboratorio de la "salvación posible". Por ello, la esperanza es, debe ser, aguantadora y rebelde, perspicaz y denodada, testaruda y reflexiva, audaz y concreta, intransigente y analítica. La esperanza en Bloch, es pues, práctica, crítica y revolucionaria.

Todo este planteamiento, propone a un sujeto histórico que sea conciente y asuma la negatividad del mundo actual y su complejidad intrínseca. La esperanza, tanto como la formulación de la utopía concreta, enfrentan sin embargo grandes retos en varios frentes: la hegemonía impulsada por las esferas del poder, como homologadora - estandarizadora de las conciencias individuales y colectivas; la dificultad del sujeto al arribo de la toma de conciencia (pasar a una conciencia crítica, para poder negar la realidad presente). Con ello, se daría un primer paso, pero es necesario que si se aspira a la estructuración de una utopía concreta se debe partir de un proyecto. Para ello, el proceso de rearticulación de su conciencia deberá lograr que el modo de apropiación del mundo sea teórico-crítico, para que pueda usar la actitud de la esperanza de manera viable. Para ello, a continuación proponemos, con base en algunas categorías, una propuesta de descubrimiento de lo real, que apunte por medio de un proyecto, a negar la contradictoriedad del mundo actual.

\section{La apropiación del conocimiento}

El objetivo de este apartado es desarrollar brevemente tres premisas que nos resultan básicas en la investigación socio-histórica: totalidad, tiempo 
y realidad. Aquí pretendemos que de ello resulte una propuesta —aunque incipiente- de conocimiento y, para enfatizarlo, de conocimiento social del presente. En esta perspectiva, el papel del sujeto adquiere una máxima significatividad toda vez que se le considera protagonista de su tiempo histórico.

Podemos decir que en la idea de ésta proposición, se concibe que hay un tiempo que deviene constantemente junto con las acciones de la sociedad, por lo cual tenemos que partir de la identificación del presente. Así, en el presente tenemos una conjugación de lo complejo de las acciones sociales y la dificultad del proceso de conocimiento, por lo que consideramos necesario tener en cuenta los tres elementos antes mencionados, a los que consideramos como elementos interactuantes entre sí.

Entendemos al tiempo presente, como una medida del acaecer humano del que se desprende lo trascendente del momento del acontecimiento estudiado y orientado hacia la búsqueda de su creciente bienestar, potenciando las posibilidades de la práctica transformadora hacia un futuro posible y deseable.

La historia actual o presente, como dimensión temporal, no carece de contenido ni se refiere a un mero parámetro cronológico, es por el contrario el lugar en que todos los elementos de diversa naturaleza tienen su expresión e interactúan; dicha interacción se presenta en dos niveles: en el tiempo en general y en la actualidad en particular; lo que permite distinguir tiempos concretos con su propia especificidad.

El presente como aquí lo concebimos es un proceso dinámico que no cesa, donde fluye un haz de acontecimientos que determinan diversas especificidades. No nos dejamos engañar por la apariencia de la quietud de la actualidad o por la errónea idea de que sobre ella nada podemos. Es verdad que lo actual se aparece como un haz de acontecimientos aislados sin una supuesta relación de necesidad existencial, pues la actualidad es 
contingente y sólo mediante un pensamiento abierto y crítico, es decir científico, se pueden desentrañar las relaciones posibles de este mar convulso que es el mundo.

Esto es importante, porque en el presente se conjugan diversas prácticas de los distintos sujetos, de los diversos grupos y clases sociales en la realidad. La historia hoy, es una arena de encuentro y de fusión de las acciones individuales y colectivas, concientes o inconscientes, organizadas o volitivas. El presente es la historia actual, es donde se vinculan los acontecimientos nuevos y la vivencia de los antiguos como nuevos. Frente a los hechos sucedidos del pasado se levantan los acontecimientos del presente articulando lo nuevo que emerge y lo viejo que no acaba de perecer (López: 1979, 23, 24).

Identificar el presente tiene el interés de hacer una proposición conceptual de aquello que se constituye en objeto de nuestra intencionalidad cognoscitiva, y con los parámetros temporales que nos permitan tener el mayor número de elementos extraídos de la interacción empírica y de los datos referenciales que sean consecuentemente integrables con los anteriores, para acceder al conocimiento del objeto en el que estamos inmersos. Objeto que deseamos apropiárnoslo con el pensamiento (epistemológico, dialéctico y crítico).

La concepción dialéctica parte de la categoría de totalidad. La construcción moderna de esta categoría se debe principalmente a Hegel. Este realiza por primera vez en la historia de la filosofía, el vínculo de la dialéctica del pensamiento con la dialéctica de la materia.

Esta nueva filosofía alemana tuvo su culminación en el sistema hegeliano, en el que por primera vez-y esto es su gran mérito-se exponía conceptualmente todo el mundo natural, histórico y espiritual como un proceso, es decir, como algo en constante movimiento, modificación, transformación y evolución, al mismo 
tiempo que se hacía el intento de descubrir en ese movimiento y esa evolución la conexión interna del todo (Engels: 1975, 9).

Sin embargo, la categoría de la totalidad corre el riesgo de asumirse en una visión reduccionista que la simplifica a la expresión vulgar de que, el todo es mayor que sus partes, o que todo está en conexión con todo, el investigador social debe tomar distancia de esta forma simplista de asumir la categoría de totalidad. Karel Kosik nos proporciona una definición marxista de la categoría de totalidad:

...pero en verdad totalidad no significa todos los hechos. Totalidad significa: realidad como un todo estructurado y dialéctico, en el cual puede ser comprendido racionalmente cualquier hecho (clases de hechos, conjunto de hechos). Reunir todos los hechos no significa aún conocer la realidad, y todos los hechos (juntos) no constituyen aún la totalidad. Los hechos son conocimiento de la realidad si son comprendidos como hechos de un todo dialéctico, esto es, si no son átomos inmutables, indivisibles e inderivables, cuya conjunción constituye la realidad, sino que son concebidos como partes estructurales del todo. Lo concreto o sea la totalidad, no es, por tanto, todos los hechos, el conjunto de ellos, el agrupamiento de todos los aspectos, cosas y relaciones, ya que en este argumento falta aún lo esencial: la totalidad y la concreción. Sin la comprensión de que la realidad es totalidad concreta que se convierte en estructura significativa para cada hecho o conjunto de hechos, el conocimiento de la realidad concreta no pasa de ser algo místico, o la incognoscible cosa en sí... (Kosik, 1968:56). 
Por su parte, en Zemelman: 1987) ${ }^{6}$, si nuestra interpretación es correcta, en su proposición conceptual, sugiere pasar del ya tradicional entendimiento del concepto de totalidad basado en la concepción de su ubicación en el nivel óntico al nivel del proceso lógico de conocimiento. El desplazamiento de la problemática de la totalidad del plano óntico al epistemológico, equivale a la cuestión básica de convertir el qué pensar en el cómo pensar sobre la realidad.

Este concepto de totalidad que obviamente ya tiene una gran tradición, ha adquirido una diversidad de sentidos, pero para Zemelman, el considerarlo dentro del nivel epistemológico tiene su virtud puesto que posee una gran capacidad para enriquecer las estructuras racionales de conexión con la realidad empírica, que permitan transformar la objetividad real en contenidos organizados.

Aquí el concepto de totalidad que refiere el autor, sirve para dos fines: primero, enriquecer las estructuras racionales de conexión con la realidad empírica, que lo entendemos como tener una dinámica racional superior a la que tradicionalmente usamos, especialmente en relación con lo que empíricamente se ha sustraído de la realidad; y, segundo, transformar la objetividad real, es decir, lo que podemos entender de lo complejo de una cosa, en contenidos organizados que pensamos que son conceptos que de acuerdo a nuestra lógica nos permiten entender los objetos.

Más adelante enfatiza que la totalidad le interesa -en términos de investigación, como fundamento epistemológico para organizar el razonamiento analítico. O sea que la totalidad es un sustento cognoscitivo para organizar la forma de conocer; es decir, es un complejo proceso de conocimiento cuya finalidad es el conocimiento.

6 Esta aportación del Doctor Zemelman Merino y otros más, nos van a permitir plantear el asunto de la construcción apropiación de objetos de estudio con base en la articulación como totalidad. A la que yo añado en concepto de transdiciplinariedda (Massé 2002) 
Pero además de hablar de la totalidad como exigencia epistemológica del razonamiento analítico, sirve, en otro nivel, para delimitar los campos de observación, lo que se puede conceptuar como “...una aprehensión que no consiste en una explicación sino que sirve para definir la base de la teorización posible" (Zemelman: 1987; 18). Si la apropiación es la abstracción sensorio-intelectiva que nos sirve para identificar los objetos con los que nos vinculamos (y de los que formamos parte, con ello, nos dice este autor, podemos aspirar a definir la base para proponer una teoría, no sólo para explicarnos los objetos de investigación. De otra manera, aunque no muy diferenciada de la anterior, para este autor, la totalidad:

Es un modo de organizar la apertura hacia la realidad que no se ciñe a permanecer dentro de determinados límites teóricos, pues se fundamenta en un concepto de lo real como articulación compleja de procesos y exige que cada uno de estos sea analizado en términos de sus relaciones con otros (Zemelman: 1987; 19).

Aquí, el concepto de totalidad ya no es un pensamiento sobre el pensamiento, ni una orientación para delimitar los campos de observación, sino la apertura del pensamiento ante la realidad, en la cual Zemelman los percibe como que se articulan, de manera compleja. Visto en una perspectiva que incluye esos sentidos del concepto de totalidad, encontramos la siguiente afirmación del autor:

En la investigación, propondremos a la aprehensión racional como solución epistemológica a la exigencia de la totalidad, cuyo mecanismo metodológico operativo es la reconstrucción articulada, mediante la cual se pueden determinar las bases para captar la realidad en condiciones de totalidad concreta, sin necesidad de partir del a priori que tenga tal o cual estructura de propiedades. Por eso es que no constituye en sí misma una explicación, sino, más bien, la 
condición para el conocimiento de lo real concreto desde toda su complejidad estructural y dinámica (Ibidem; 20).

Podemos entonces decir que para Zemelman, la concepción de totalidad es una actividad intelectiva con un sentido orientado al proceso cognoscitivo, que sirve de base para la reconstrucción de lo perceptible, ello lo podemos observar en la siguiente aseveración:

...los elementos o niveles componentes de la totalidad, son teorizables sólo en función de su relación posible con el "todo". El "todo" es el que da sentido a las partes en cuanto las incluye; las partes, a su vez, son el movimiento de esa inclusión. Sin embargo, el "todo" no alude a un "todo" real sino a una exigencia de totalizar lo fragmentario; no implica al movimiento como realidad sino como construcción que se aprehende en tanto constituyéndose y no como ya constituido...lo que se pretende es avanzar en un intento por trasladar la discusión filosófica acerca de la categoría de totalidad, al plano epistemológico, directamente relacionado con la construcción del conocimiento concreto (Zemelman: 1987; 20).

El concepto de totalidad de Zemelman establece toda una serie de potencialidades que pueden incidir en los diversos procesos de la investigación. Así, del recorrido que realiza para identificar los diversos sentidos del concepto, concluye que:

1) Las funciones que cumple la totalidad son: organizar una forma de razonamiento crítico que permita romper o traspasar la apariencia de los fenómenos. Desde la perspectiva de la totalidad, la apariencia es un nivel de la realidad que no está analizado en su articulación; así como, a contrario sensu, lo real es un nivel de la realidad analizado en su articulación; y

2) la categoría de la totalidad está claramente referida a la idea de movimiento, sin referirse a la estructura dinámica particular que pueda asumir 
el movimiento (que es lo propio de la contradicción). Por eso, la totalidad contribuye a delimitar el movimiento real para facilitar su explicación como objeto particular; de ahí que se le vincule con la idea de la realidad como exterioridad mutable. Por lo que, sin incurrir necesariamente en afirmaciones acerca de su estructura, cumpla la función de una exigencia epistemológica para construir el conocimiento objetivo.

Lo anterior significa distinguir dos aspectos en la discusión sobre la totalidad:

a) La totalidad como recurso metodológico...y

b) La totalidad como enfoque epistemológico de la realidad que exige concebirla como un complejo de niveles con sus propios requerimientos para su captación racional; y que principalmente son dos:

1) tomar en cuenta la complejidad tiempo espacial de los procesos reales, en forma de no reducir la articulación a parámetros homogéneos, y 2) no identificar la totalidad como una estructura de determinaciones, esto es, con un modelo teórico.

En suma, la totalidad es la articulación dinámica de los procesos reales caracterizada por sus dinamismos, ritmos temporales y despliegues espaciales; y esta articulación puede concretarse en diferentes recortes del desarrollo histórico" (Ver Zemelman: 1987: 20)

La identificación de los diversos momentos, niveles aproximaciones e interacciones en el proceso de conocimiento, son las premisas de la propuesta de Zemelman, lo que llega a constituir en sí, otro objeto de atención para el conocimiento; y es innegable que las posibilidades de su implementación son inmensas, ya que, involucrarse en cualquier proceso de investigación requiere tener una visión amplia. Ello, se puede desprender de lo que el mismo autor afirma:

...el planteamiento de la totalidad puede considerarse como una alternativa que define una línea de reflexión 
de grandes potencialidades. Es un procedimiento racional que permite establecer una base de razonamiento que puede servir para sistematizar una reflexión sobre prácticas investigativas ya cristalizadas, pero también para desarrollar formas de pensar que no necesariamente sean un reflejo de aquéllas (Ibidem: $1987 ; 61)$

\section{La apropiación de conocimiento con base en la articulación transdisciplinaria}

Es la capacidad de apertura hacia lo real de la totalidad, lo que permite profundizar mayormente en la realidad con el objetivo de dar prioridad a la construcción del objeto. La totalidad así concebida deviene como un método que hace posible el recorte o construcción del objeto. Este último sin embargo nos plantea una importante pregunta: ¿Cuáles son los fundamentos de conocimiento implícitos que están en conexión con un concepto de totalidad de la forma que se plantea?

La necesidad de una apertura de la razón como actitud abierta a la especificidad de lo real, para el entendimiento de la interacción que existe entre la multiplicidad de objetos (incluyendo a sujetos sociales concretos) posibles en el mundo real. Estos y sus interacciones existentes son susceptibles de captación con base en los conceptos de especificidad, realidad dinámica y la perspectiva de totalidad como recurso epistemológico.

Para proceder tanto a la construcción - apropiación del objeto de estudio, así como a su teorización posible, Zemelman (1987) plantea la necesidad de tener un control de los condicionamientos de la razón que impiden la objetividad del conocimiento, imprimiendo sesgos en los análisis. Se intenta evitar, las determinaciones a priori, de sucesos que provienen de nuestro esquema referencial teórico, ideológico o de la 
experiencia, para dar paso a una visión que, concibiendo al mundo como un universo de la mayor complejidad, pueda descubrir lo específico concreto de las conexiones determinantes del hecho real.

Para ello se esbozan los mecanismos metodológicos para la construcción del objeto como reconstrucción articulada e histórica; aprehendiendo su especificidad con base en la articulación transdisciplinaria para el descubrimiento de las conexiones determinantes del objeto, con otras dimensiones de lo real.

La articulación transdisciplinaria, quiere decir, pensar al objeto más allá de los límites a que puede circunscribirlo cualquier discurso sustantivo (disciplinario). No obstante, recomienda usar las categorías y conceptos con carácter abierto. Por ejemplo, la categoría modo de producción de Marx está abierta y sirve para captar cualquier modo de producción; pero hasta que el sujeto cognoscente se enfrenta con un pensamiento abierto al modo de producción concreto (objeto de estudio), y después de pensarlo en términos de totalidad, es que puede decir el tipo de modo que es y no antes. En el estudio de Marx, El Capital, encuentra que dicho modo es un modo de producción capitalista. Pero este último adjetivo, solo aparece en Marx, una vez que ha descubierto la lógica interna de su objeto, el ser del Capital.

De lo anterior nos previene Zemelman, al decir que no hay que asignarle determinaciones a priori al objeto nuevo que queremos construir o, con Covarrubias, el objeto que nos queremos apropiar. No podríamos decir por ejemplo, que vamos a estudiar el "modo de producción capitalista" en los artesanos de Mitla, Oaxaca, porque lo más probable sea, que dicho modo de producción no sea capitalista sino de sobrevivencia; es decir, no creemos que dicho modo de producir, reúnan las características definitorias de ser capitalista, pues no parece posible que dichos artesanos generen "plusvalor". Es a esto a lo que nos referimos con Zemelman, al control de 
los condicionantes teóricos, pues el adjetivo capitalista, recoge el análisis de Marx, al que llega después de un profundo y documentado análisis, resultado de descubrir o develar la logicidad del objeto modo de producción (este existe en la realidad en los talleres de la producción industrial; pero también existe en el pensamiento, como categoría de análisis. En el caso de los artesanos de Mitla, lo más probable, de hacerse una investigación, es que se llegara a la conclusión de que es un modo de producción de autosubsistencia.

Una normativa más retomada de Zemelman, es el control de la experiencia. No pensar que por haber abordado objetos similares en el pasado, podemos asignarle características parecidas al nuevo objeto. En una anécdota que escribe Karl R. Popper en su autobiografía, cuando decidió dejar de trabajar para el famoso Psicólogo Adler, en la que relata que, en menos de cinco minutos diagnosticó a un paciente; a lo que Popper protestó preguntando ¿Cómo puede usted estar tan seguro? A lo que Adler contestó: "por mi experiencia de mil casos". Probablemente el Doctor tenía razón, al fundar su diagnóstico, pero si lo que pretendemos es una propuesta seria, no podemos caer en una simplicidad de ese tipo sólo por sobre-confiar en nuestra experiencia. En la perspectiva dialéctica crítica, las especificidades temporales de los objetos son de vital importancia, pues en muchos de los casos, se trata de los momentos de inicio de una práctica de determinados sujetos histórico concretos. En esta visión, la volición política es una premisa de las más importantes de la construcción-apropiación del conocimiento.

Con respecto al control de los condicionantes ideológicos, creemos que se debe distinguir la lógica del objeto (su ser) de nuestros deseos de futuro (deber ser). El deseo de futuro deberá ser tratado de otra forma. ¿Cómo? Convirtiendo a la ideología en objeto de estudio, en problema a dilucidar, no como marco explicativo del objeto. El deseo de futuro también es posible de convertirlo en objeto de estudio, para lo cual es 
necesario construir un proyecto, a sabiendas que, en el movimiento de lo real se encuentra la contingencia. Esta es también es parte constitutiva de aquélla, al igual que la complejidad, el conflicto y el caos de la sociedad, como realidad. Aquí consideramos que un proyecto de futuro, no se detiene tanto en teorizar un deber ser, como a practicar una actitud -con Bloch-, práctica, crítica y transformadora en donde el proyecto sirve de guía para la acción.

Lo que planteamos como transdisciplinario es eso. Construir el conocimiento por articulación de niveles multidimensionales de lo real, y al hecho de relevar el "descubrimiento" de la lógica del objeto, no sólo para explicarlo, sino para teorizar, o para actuar sobre él. Metodológicamente pues, queremos relevar "la cosa", el objeto, por encima de cualesquier límite impuesto por tal o cual estructura teórica preestablecida, pero sin desechar a priori las posibilidades de captación de lo real de las categorías y conceptos de constructos teóricos ya construidos.

Estos son en síntesis los elementos constitutitos de una propuesta, para la construcción (pero también para la teorización de objetos socioeducativos), que no se limiten a explicaciones simplistas con base en la prueba de una o dos hipótesis (método hipotético deductivo), pues partimos de que la realidad está, más en espera de ser teorizada e incidida, que esperando simplemente ser explicada.

\section{Conclusiones}

Se considera haber mostrado cómo la totalidad dialéctica crítica, con base en la epistemología dialéctica crítica puede ser un importantísimo dispositivo que ya se utiliza para la apropiación del conocimiento de lo real. Para ello, se expusieron algunas de las limitaciones del conocimiento disciplinario porque fragmenta a la realidad, supeditándola a sus límites 
teóricos; pues las teorías son aproximaciones conceptuales de lo real. Por ello, al exponer nuestros conceptos de realidad, presente y utopía, mostramos lo limitado del proceso hipotético deductivo con base en los discursos disciplinarios; con esas bases, es que propusimos un pensamiento más abierto y no sujeto a delimitados alcances teóricos, a través de controlar las predeterminaciones ideológicas, teóricas y de la experiencia, así como los "ruidos" que causan los referentes "atéoricos" en el momento de apropiarse del conocimiento de lo real. Es decir, para producir conocimiento científico.

\section{Referências}

AGUILAR V., L. F. Ernst Bloch, Filósofo de la Utopía. Revista de Filosofía de la UIA, México, pp. 21-36, 1997.

BLOCH, E. Sujeto objeto. El pensamiento de Hegel. ed. FCE. México: trad. Wenceslao Roces, José María Ripalda, Guillermo Hirata y Justo Pérez del Corral, 1983.

COVARRUBIAS V., F. La teorización de procesos histórico - sociales. Volición, ontología y cognición científica. México, SEP-UPN, col. Textos No. 4, 1995b.

GONZÁLEZ V. F. Ernst Bloch y el Derecho Natural, en: A favor de Bloch; varios autores, Madrid, ed. Taurus, serie ensayistas - 171, pp. 51,1979.

GUTIÉRREZ P.,J. De cómo la metodología inhibe la investigación, en: Docienso, Revista del Doctorado Interinstitucional en Ciencias Sociales y Humanidades; año 1 número 2, enero-junio de 2002, pp. 51 - 80, 2002.

GEGEL, H. G. Fenomenología del espíritu, ed. FCE; trad. Wenceslao Roces, 1978.

IBÁÑEZ, J. Del algoritmo al sujeto. Perspectivas de la investigación social, Siglo XXI de España, 1985.

IVANIER, A. Política y Representación: construcciones hegemónicas en las ciencias sociales. Ponencia presentada en la Conferencia Internacional de Sociología de la Educación. Buenos Aires, agosto de 2004. 
KOSIK, K. Dialéctica de lo concreto. México: Grijalbo, Trad. Manuel García Morente y Manuel Fernández Núñez, 1968.

LEVY-Leblond et. al. (Coomps). (Auto)crítica de la ciencia. México: Nueva Imagen, trad. Eva Grosser Lerner, 1980.

LÓPEZ, J. S. El análisis de coyuntura en el pensamiento socialista clásico. Revista Mexicana de Sociología. México: enero - marzo de 1979, pp. 23-58, 1979.

MASSÉ, C. Hacia una dialéctica transdisciplinaria en la construcción de conocimiento científico social como respuesta a la crisis del paradigma disciplinario - fragmentario, en Massé y Pedroza (Coords.), La complejidad en las ciencias. Método, Institucionalización y enseñanza, ed. El Colegio Mexiquense, A. C.; pags. $75-106,2002$.

MORÍN, E. Introducción al pensamiento complejo, en col. Hombre y Sociedad. Barcelona: Gedisa, 1997.

OLIVÉ, LEÓN. Estado, legitimación y crisis. Crítica de tres teorías del Estado capitalista y de sus presupuestos epistemológicos. México, Siglo XXI, 1985.

POPPER, K, R. Búsqueda sin término: una autobiografía intelectual, Madrid, Tecnos, 1977.

ZEMELMAN, H. Uso crítico de la teoría. En torno a las funciones analíticas de la totalidad. México:Ed. Universidad de las Naciones Unidas El Colegio de México, 1987. 


\section{Resumen}

El trabajo parte de mostrar las limitaciones de los discursos sustantivos disciplinarios. Enseguida se expone la complejidad los conceptos de realidad, presente y utopía, para con ello, discutir cómo ocurre la producción de conocimiento científico, pero alertando al lector, sobre sus límites frente a la contradictoriedad de lo real. Frente a las contingencias imprevistas que siempre se presentan en dicho proceso, se exponen las categorías de Esperanza y Utopía, para finalmente proponer una apropiación del conocimiento, como conocimiento científico a través de una articulación transdisciplinaria, que garantice la apropiación de la complejidad de lo real, como totalidad.

Palabras-clave: Epistemología, totalidad, dialéctica, conocimiento científico, contradicción, utopía, esperanza, articulación, presente, realidad y transdiciplinaria.

Recebido: $13 / 11 / 2005$

Aceite final: 14/12/2005 


\section{Complexity in dialectical totality}

\section{Carlos Massé Narváez}

This works starts by showing the limitations of disciplinary substantive discourses. Then it presents the complexity of the concepts of reality, present, and utopia, in order to discuss how production of scientific knowledge takes place, but warning the reader about its limits in face of the complexity of the real. Given the unpredictable contingencies that always emerge in that process, the categories of Hope and utopia are presented in order to finally put forward appropriation of knowledge as scientific knowledge through disciplinary articulation that guarantees the appropriation of the real as a totality.

Key words epistemology, totality, dialectics, scientific knowledge, contradiction, utopia, hope, articulation, present, reality, and transdisciplinar. 